\title{
Part IV Modules of Maintenance of Certification
}

Every American Board of Family Medicine (ABFM) Diplomate will be required to complete a Part IV module during the Maintenance of Certification for Family Physicians (MC-FP) process. PPMs, the ABFM's Part IV modules, are webbased, quality improvement modules in health areas which generally correspond to the Self-Assessment Modules.

Each physician will assess his or her care of patients using evidence-based quality indicators. After a physician enters data from 10 patients into the ABFM website, feedback is provided for each of these quality indicators. The performance data are used by the physician to choose an indicator for which a quality improvement plan will be designed. Using a menu of interventions available from various on-line sources, the physician designs a plan of improvement, submits the plan, and implements the plan in practice. After a minimum of 3 months, the physician assesses the care provided to 10 patients in the chosen health area and inputs the data to the ABFM website. The physician then is able to compare pre- and postintervention performance and compare their results to those of their peers. Evidence of improvement is not required to satisfy this MC-FP requirement.

Part IV modules include the Performance in Practice Module (PPM), approved alternatives, and now available, the Methods in Medicine Module (MIMM) as well as the American Board of Medical Specialties (ABMS) Patient Safety Improvement Program.
Roughly $20 \%$ of ABFM Diplomates practice in environments in which they do not have access to a continuity practice that they can use for PPMs. The MIMMs now provide a Part IV alternative for Diplomates in these professional roles. The MIMM is designed to mirror the process of preintervention audit, the conduct of a quality improvement activity, and the postintervention audit used in the PPMs. The PPM and the MIMM modules are included in the MC-FP process fees.

Diplomates can access the ABMS Patient Safety Improvement Program through the ABFM website or at www.healthstream.com/hlc/abfm/. Diplomates will be asked to $\log$ in and pay a fee of $\$ 55$ dollars to HealthStream, the organization which delivers the module for ABMS. You will also be required to provide your ABFM ID\# to HealthStream in order for the ABFM to confirm your completion of the Patient Safety Improvement Program. Once you've provided HealthStream with your ABFM ID\#, the ABFM will access your records with HealthStream and award the MC-FP credit for completing the Patient Safety Improvement Program as long as ABFM MC-FP fees are current.

If you need help with logging in or completing modules, or if you have any questions regarding your current MC-FP status, please contact our Support Center at $877-223-7437$ or via e-mail at help@theabfm.org for assistance.

Robert Cattoi American Board of Family Medicine 